\title{
FENOLOGÍA DE PALMERAS ARBORESCENTES NATIVAS DE MADRE DE DIOS - PERÚ
}

\author{
PHENOLOGY OF ARBORESCENT PALMS NATIVES FROM MADRE DE DIOS - PERU
}

Marisabel Ureta Adrianzén, Paola Martínez Gonzales, Raúl Tupayachi Trujillo y Alfonso Zúñiga Hartley

\begin{abstract}
RESUMEN
La fenología reproductiva de siete especies de palmeras arborescentes, correspondientes a 176 individuos fue estudiada durante 34 meses, entre julio 2005 y mayo de 2008, en Madre de Dios, Perú. Las observaciones mensuales consideraron dos fenofases a evaluar: floración (botones florales y flores) y fructificación (frutos inmaduros y maduros), cuyos porcentajes de producción fueron reducidos a 5 categorías. La floración se produjo durante la temporada de mayor precipitación o época húmeda y la fructificación se presentó en la transición de época seca a época húmeda. Mauritia flexuosa presenta los valores más altos de floración y fructificación, que junto con Socratea exorrhiza, Euterpe precatoria, Oenocarpus bataua, Iriartea deltoidea, Astrocaryum murumuru y Attalea butyracea demuestran ser componentes integrales para la conservación de ecosistemas con funcionalidad hídrica, así como también constituyen parte fundamental en la dieta de diversos herbívoros amazónicos, garantizando de esa manera su distribución y densidad en los bosques amazónicos de Madre de Dios.
\end{abstract}

PALABRAS CLAVE: fenología reproductiva, palmeras arborescentes, bosques amazónicos, Madre de Dios

\begin{abstract}
The reproductive phenology of seven species (176 individuals) of arborescent palms was evaluated over 34 months (from May 2005 to July 2008) in Madre de Dios - Perú. Monthly observations considered and evaluated two phenophases: flowering (buds and flowers) and fructification (immature and ripe fruits), whose production percentages were reduced to 5 categories. Flowering occurred during the rainy season, and fructification occurred in the transition period from dry to rainy season. Mauritia flexuosa showed the highest flowering and fruiting values, that together with Socratea exorrhiza, Euterpe precatoria, Oenocarpus bataua, Iriartea deltoidea, Astrocaryum murumuru and Attalea butyracea are shown to be fundamental components for the conservation of hydraulic lift ecosystems as well as an essential part of the diet of many Amazonian herbivore species thus ensuring their distribution and density in the rainforests of Madre de Dios.
\end{abstract}

KEY WORDS: reproductive phenology, arborescent palms, rainforest, Madre de Dios

\section{INTRODUCCIÓN}

Las palmeras son plantas tropicales por excelencia, pertenecen a la familia Arecaceae, comprenden alrededor de 189 géneros y 3000 especies (Cabrera y Wallace, 2007). En América existen cerca de 67 géneros y 550 especies y 33 géneros, la mayoría de los cuáles (30) poseen especies arborescentes; adicionalmente en el Perú se registran 145 especies (Pennington et al., 2004).
Así mismo, el Perú cuenta con 9 especies endémicas, que ocupan áreas desde la Amazonía hasta los bosques montanos orientales, entre 130 y 3000 msnm (León et al., 2006).

Las palmeras son diversas y abundantes en los bosques húmedos tropicales (Rojas-Robles et al., 2012) con un significativo valor social y económico sobre las demás plantas, la mayoría de sus estructuras son útiles para la 
construcción, las fibras para tejer, las hojas para techar y sobre todo sus brotes, frutos y semillas comestibles para los mamíferos, aves, peces, insectos y otros animales (Wallace, 1853), siendo un recurso importante en la biología y ecología de la Amazonía.

Por ser un recurso tan elemental y abundante en la producción de frutos en la Amazonía, las palmeras son adecuadas para investigaciones a mediano y largo plazo que involucren la evaluación de patrones fenológicos, ya que cuentan con singulares e independientes eventos de floración y fructificación (Peres, 1994) que varían entre géneros y especies a pesar de tratarse de una misma familia. Las Arecaceae ocupan casi todos los hábitats, especialmente las zonas tropicales y subtropicales del mundo (Henderson et al., 1995) pero aún no se cuenta con información detallada de su fenología reproductiva, los estudios existentes registran cierta influencia del grado de estacionalidad en las condiciones meteorológicas particulares de cada área de estudio dentro del Neotrópico (Wallace, 1853; Kahn, 1991; Ibarra-Manríquez, 1992; Storti, 1993; Seres y Ramírez, 1993; Peres,1994; Wyatt y Silman, 2004; Haugaasen y Peres, 2005; Cabrera y Wallace, 2007, Tupayachi et al., 2007).

La importancia económica reconocida a nivel mundial de la familia Arecaceae es inmensa. En el Perú, innumerables investigaciones de sus múltiples usos reportan que todas las partes de las palmeras son aprovechables, como las hojas (techados, paredes, cestería, fibras); pecíolos (piezas de construcción, cestería, esteras, flechas); troncos (paredes, pisos, puertas, almidón, cerbatanas); palmitos; frutos (alimento, aceite, carbón) y algunas raíces para medicina tradicional (Kahn y Mejía, 1987). Adicionalmente, se conocen especies productoras de aceites como Oenocarpus bataua, estos aceites no tienen uso culinario únicamente, sino que también se utilizan en la cosmética del cabello y la lubricación de herramientas y armas; otras especies son fuente de frutos comestibles y de almidón como Mauritia flexuosa. Cabe destacar la importancia económica de M. flexuosa en el Perú, es la palmera más frecuente y sobresaliente en la Amazonía peruana, se conoce que aproximadamente en la ciudad de Iquitos se consumen $12000 \mathrm{~kg}$ de sus frutos diariamente, además de su tronco se obtiene un almidón comestible conocido como miel de aguaje y en el tronco cortado de los individuos masculinos en descomposición se desarrolla el "suri"
Rhynchophorus palmarum, un coleóptero comestible parte del un típico menú amazónico (Del Castillo et al., 2006). M. flexuosa también es aprovechable en bebidas y helados, sus hojas son útiles para techar y sus troncos para hacer casas (paredes y pisos) en algunas zonas rurales, las fibras proporcionadas por las hojas son empleadas para confeccionar canastos, esteras y artesanía, es por eso que son considerados entre las etnias nativas amazónicas como "el símbolo de la inmortalidad" y denominada "el árbol de la vida" por Alexander von Humboldt. El estudio de Guzmán (2004) mostró que es la especie con la mayor capacidad para almacenar carbono en la amazonía, almacenando entre 480 a 600 tn/ha como ecosistema de bosques hidrometamórficos comúnmente llamados "aguajales" en nuestro país, almacena entre tres y cinco veces más que cualquier otro ecosistema tropical, agregándole un valor ecosistémico y ecológico bastante sobresaliente.

Otras palmeras de importancia económica son Astrocaryum murumuru y Attalea butyracea, ambas tienen uso medicinal, cosmético, alimenticio (frutos y semillas) y como material para la confección de herramientas y utensilios (hojas para cestería y escobas). Las palmas son también las proveedoras del "palmito" que es el ápice comestible del estípite; aunque se consume el "palmito" de la mayoría de especies de palmeras en la Amazonía peruan, existe una gran predilección por los de la especie Euterpe precatoria, ya que forma parte de las tradiciones étnicas en las comunidades amazónicas. Igualmente, se tiene a las especies usadas para construcción como Iriartea deltoidea y Socratea exorrhiza en el caso de construcción de pisos de paredes, como vigas de construcción techos y el uso como postes de vivienda y cercos (Balslev et al., 2008).

Este estudio se realizó bajo el programa de disponibilidad vegetal del proyecto AREAS-Amazonía; que ha permitido colectar información para la conservación de la fauna silvestre en la Amazonía peruana, contribuyendo así al diseño y la gestión de áreas naturales protegidas. Con el presente estudio se busca proveer información detallada sobre la fenología reproductiva de palmeras arborescentes amazónicas y alcances sobre su importancia en la disponibilidad de frutos para las especies dispersoras y depredadoras de semillas y su comportamiento en dos localidades en los bosques amazónicos de Madre de Dios. 


\section{MATERIALES Y MÉTODOS}

El estudio se realizó en dos localidades en el departamento de Madre de Dios al sureste del Perú, entre julio 2005 y mayo 2008. La primera localidad, Los Amigos, pertenece a la Concesión para la Investigación Río Los Amigos (ACCA) con un área de $1450 \mathrm{~km}^{2}$. El trabajo de campo se llevó a cabo en los bosque próximos al Centro de Monitoreo $\mathrm{N}^{0} 1$ situado a orillas de los Ríos Madre de Dios y Los Amigos. El área comprende un sistema de trochas de 3 a $8 \mathrm{~km}$ de largo, ordenadas en una grilla para evaluar un área de aproximadamente $35,99 \mathrm{~km}^{2}$. (12 $\left.{ }^{\circ} 30^{\prime}-12^{\circ} 36^{\prime} \mathrm{S}, 70^{\circ} 02^{\prime}-70^{\circ} 09^{\prime} \mathrm{W}, 250-320 \mathrm{msnm}\right)$. La segunda localidad, Tambopata, se ubica entre el Parque Nacional Bahuaja Sonene y la Reserva Nacional de Tambopata, limitada al oeste por el Río Tambopata y al este por la Quebrada Gato. En este lugar se elaboró un sistema de trochas que ocupa un área de muestreo de $65 \mathrm{~km}^{2}\left(12^{\circ} 57^{\prime}-13^{\circ} 01^{\prime} \mathrm{S}, 6^{\circ} 25^{\prime}-69^{\circ} 30^{\prime} \mathrm{W}, 200-250\right.$ msnm). Según la clasificación de Zonas de Vida de Holdrige (1987) la región de Madre de Dios pertenece a la Zona de Vida de Bosque Húmedo Tropical de Transición a Subtropical (bh-T/S), donde se observan las siguientes formaciones vegetación: Bosques de colina (relieve ondulado, suelos arcillo arenosos y con poca capacidad para retener agua, también poca materia orgánica); Bosque de quebrada (localizado a ambas márgenes del Quebradas); Bosque de terraza alta y baja (sobre superficies relativamente planas y suelos arcillo-arenosos); Bosque de bají (conocidos como bajial, inundables), (Encarnación, 1993; Vega et al., 2006; Tobler et al., 2008). Según los datos tomados por ATRIUM version 1.8 (on-line) se realizó un climatograma que incluye la precipitación y temperatura, ambos parámetros se muestran con valores promedio anuales entre julio 2005 a mayo 2008 (Figura 1).

En los cuatro años de muestreo se reportó una precipitación total entre los 761,6 a 3388,4 mm (1874,2 $\mathrm{mm}$ en promedio) y precipitaciones promedio anuales entre los 197,8 a 282,3 mm (200,9 mm en promedio). En general el comportamiento de la precipitación fue unimodal en el 2006, con un pico máximo en enero con 410,1 mm. En el 2007 tuvo un comportamiento bimodal, el primer pico se alcanzó en febrero con 445,6 $\mathrm{mm}$, seguido por un incremento notable en octubre con 490,9 mm. La temperatura mostró un comportamiento unimodal en marzo del 2006 y 2008 con valores de hasta $25,7^{\circ} \mathrm{C}$, pero en el 2007 sólo muestra un valor máximo durante enero, febrero, marzo y abril $\left(24,2{ }^{\circ} \mathrm{C}\right.$ en promedio), con un posterior descenso entre mayo, junio, julio y agosto $\left(21,3{ }^{\circ} \mathrm{C}\right.$ en promedio) para luego incrementar en los meses posteriores hasta un máximo de $24,7{ }^{\circ} \mathrm{C}$ durante octubre, coincidentemente el mismo valor más alto en la precipitación (Figura 1).

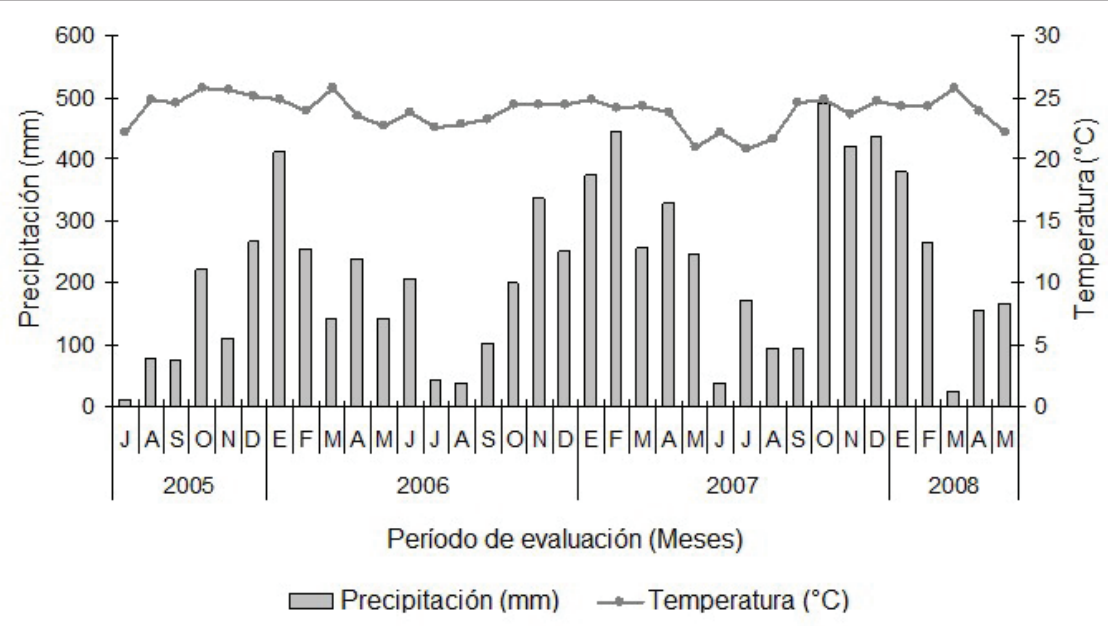

62

Figura 1. Precipitación y temperatura mensual para los años 2005-2008, Madre de Dios. Datos de Atrium (BRIT). 
La comunidad de palmeras arborescentes en Madre de Dios estuvo representada por 12 especies, de las cuales se eligieron 7 especies nativas para este estudio: Astrocaryum murumuru Mart. 1824, Attalea butyracea (Mutis ex L. f.) Wess. Boer 1988, Euterpe precatoria Mart. 1842, Iriartea deltoidea Ruiz \& Pav. 1798, Mauritia flexuosa L. f. 1782, Oenocarpus ataua Mart. 1823 y Socratea exorrhiza (Mart.) H. Wendl. 1860, (Tabla 1). Todas las especies de palmeras arborescentes evaluadas son monoicas, a excepción de la especie $M$. flexuosa que es dioica, evaluando en esta especie tanto individuos femeninos y masculinos. La fenología de las palmeras se evaluó dentro de trochas en ambas localidades. En Los Amigos se usaron como transectos de monitoreo fenológico las trochas existentes en el área (Figura 2a) que incluyen bosque de bajío y terraza baja, difiriendo del bosque de Tambopata en el cual se elaboró un sistema de trochas que atraviesa bosques de bajío, terraza y colina (Figura 2b). Para el muestreo se realizaron transectos lineales de hasta $10 \mathrm{~m}$ en donde se seleccionó y marcó con placas metálicas numeradas a 5 individuos de cada especie de palma a ambos lados del transecto con un mínimo de 5 individuos y un máximo de 18 individuos (Tabla 1). Para la selección de los individuos se consideró: a) individuo adulto con $\mathrm{DAP} \geq 10$ $\mathrm{m}$, capaz de producir flores y frutos, b) con la copa libre de infestaciones de lianas, epífitos y estranguladores. Así mismo, se consideraron dos temporadas bien definidas: a) época húmeda: consideró meses de duración entre noviembre a abril, y b) época seca: consideró meses de duración entre mayo a octubre.

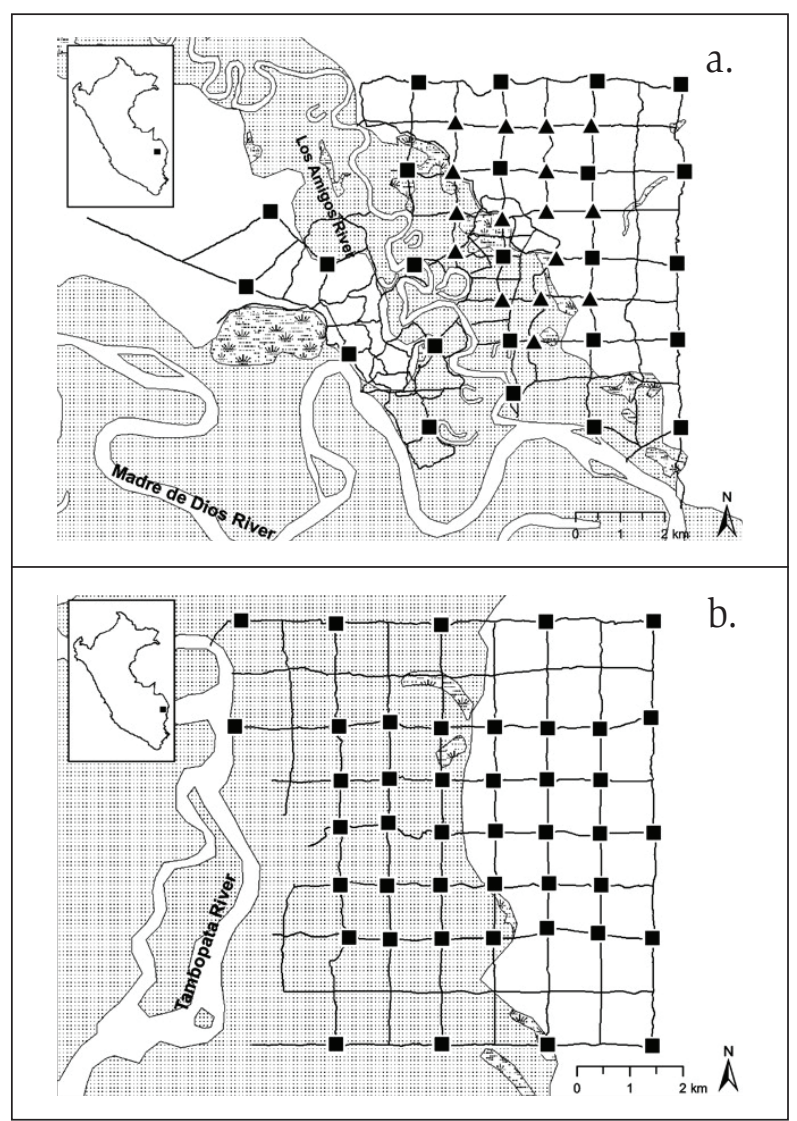

Figura 2. a) Área de muestreo en la localidad de Los Amigos, área perteneciente a la Asociación para la Conservación de la Cuenca Amazónica (ACCA). b) Área de muestreo en la localidad de Tambopata, sistema de grillas elaborado dentro del proyecto AREAS-Amazonía (WWF) para el monitoreo de mamíferos superiores.

Tabla 1. Abundancia de palmeras arborescentes con placas metálicas numeradas y evaluadas por cada localidad de muestreo.

\begin{tabular}{llccc}
\hline \multicolumn{1}{c}{ Especie } & Nombre vernacular & Los Amigos & Tambopata & Población total \\
\hline Astrocaryum murumuru & Hicungo & 12 & 15 & 27 \\
Attalea butyracea & Shapaja & 5 & 12 & 17 \\
Euterpe precatoria & Huasaí & 17 & 13 & 29 \\
Iriartea deltoidea & Pona & 17 & 12 & 20 \\
Mauritia flexuosa & Aguaje & 13 & 7 & 25 \\
Oenocarpus bataua & Ungurabi & 18 & 11 & 28 \\
Socratea exorrhiza & Cashapona & 17 & $\mathbf{7 7}$ & $\mathbf{1 7 6}$ \\
\hline \multicolumn{1}{c}{ Total } & & $\mathbf{9 9}$ & & 25 \\
\hline
\end{tabular}


Las observaciones fenológicas se realizaron mensualmente de forma directa con binoculares (Nikon y Bushnell de 10x42) por dos personas por un período de tres años durante julio 2005 - mayo 2008 (Tabla 1). Se consideraron dos fenofases a evaluar: floración y fructificación. Para cuantificar cada fenofase se los porcentajes de producción se dividieron en 5 categorías $(1=0-20 \%$; $2=21-40 \% ; 3=41-60 \% ; 4=61-80 \% ; 5=81-100 \%)$ como lo sugiere la metodología propuesta por Fournier (1974), y otros estudios (Loayza et al., 2006; Tupayachi et al., 2007; Cabrera y Wallace, 2007). Para complementar las observaciones se colocaron trampas colectoras cuadradas de 1 x $1 \mathrm{~m}$ con un tamiz $\mathrm{N}^{\circ} 18$ (apertura de $1 \mathrm{~mm}$ ) para visualizar de cerca el tamaño y forma de las flores y frutos de cada especies, así mismo se cuantificó la duración del tiempo de floración y fructificación entre individuos de cada especie a partir del promedio ( \pm desviación estándar) de cada fenofase para medir y clasificar los patrones fenológicos (patrón continuo: floración y fructificación cesan esporádicamente y por poco tiempo; patrón subanual: es irregular y poco entendido, floración y fructificación ocurren en cualquier época del año y en intervalos variables; patrón anual: tiene un solo episodio de floración y fructificación al año; patrón supranual: tiene episodios de floración o fructificación en ciclos de varios años) según metodología de Newstron et al. (1994).

\section{RESULTADOS}

A manera de sucesos poblacionales en Los Amigos, la floración de 6 especies evaluada presentó patrones subanuales (Figura 3a) mostrando picos máximos y mínimos a intervalos irregulares durante los cuatros años evaluados, con el pico más sobresaliente durante el 2005 en el mes de noviembre para M. flexuosa. A. butyracea presentó un patrón anual. Posteriormente, la fructificación presenta los mismos patrones que en la fenofase anterior (Figura 4a), pero además se observa un patrón anual entre el 2006 y 2007 para M. flexuosa, y entre el 2007 y 2008 para S. exorrhiza.

Por otro lado, en Tambopata, la floración de casi todas las especies evaluadas mostró patrones subanuales principalmente (Figura 3b), reportando una asincronía respecto a la producción de flores a lo largo de cada año con el pico más alto en noviembre alcanzado por $M$. flexuosa. A diferencia de las demás especies, $O$. bataua mostró un patrón continuo durante el 2007 alcanzando un pico más elevado en marzo del mismo año. Durante la fructificación (Figura 4b) se hace más notorio un patrón continuo y supranual, como sucede con las especies S. exorrhiza, I. deltoidea y O. bataua, principalmente.

S. exorrhiza e I. deltoidea fueron las especies dominantes de los Bosques de terraza en ambas localidades de estudio, mostrando en ambos sitios una gran abundancia y densidad de individuos.

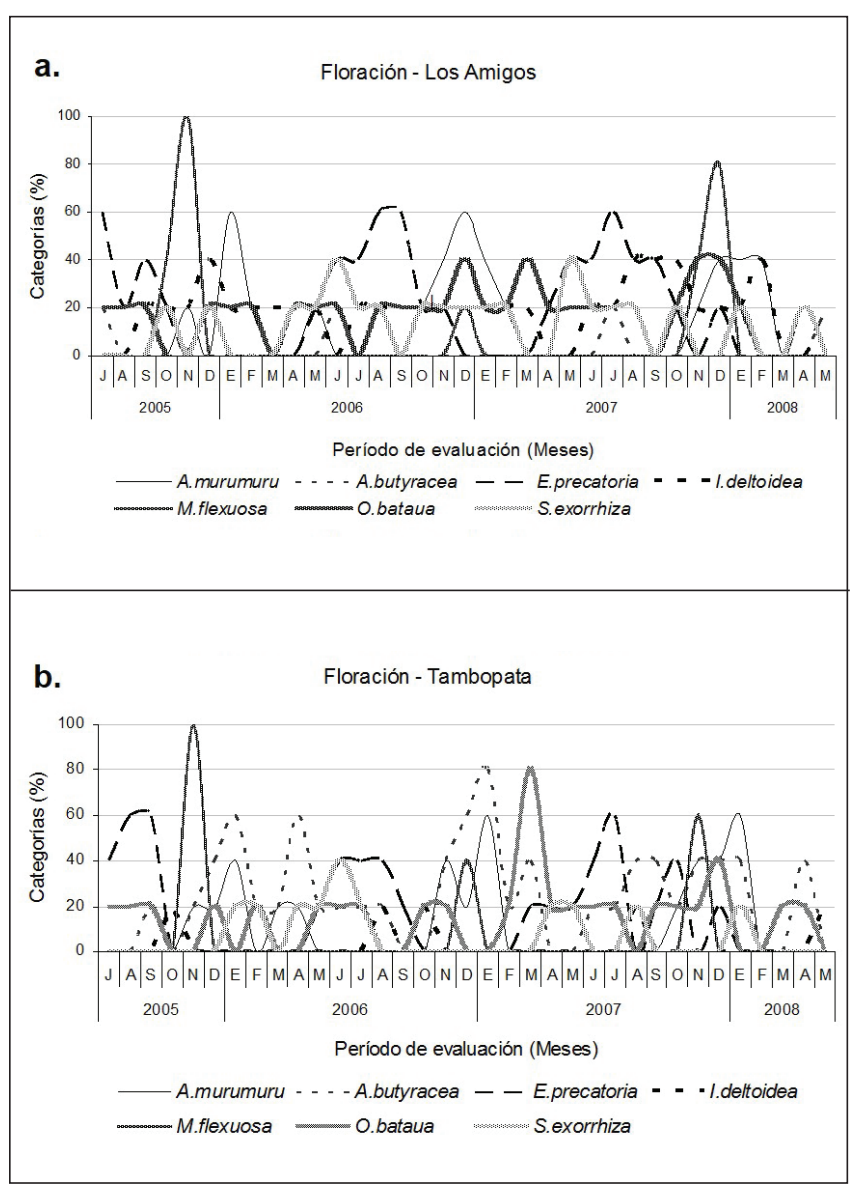

Figura 3. Patrones de floración poblacional de las palmeras arborescentes nativas evaluadas en el período julio 2005-mayo 2008 en la localidad: a. Los Amigos. b. Tambopata. 


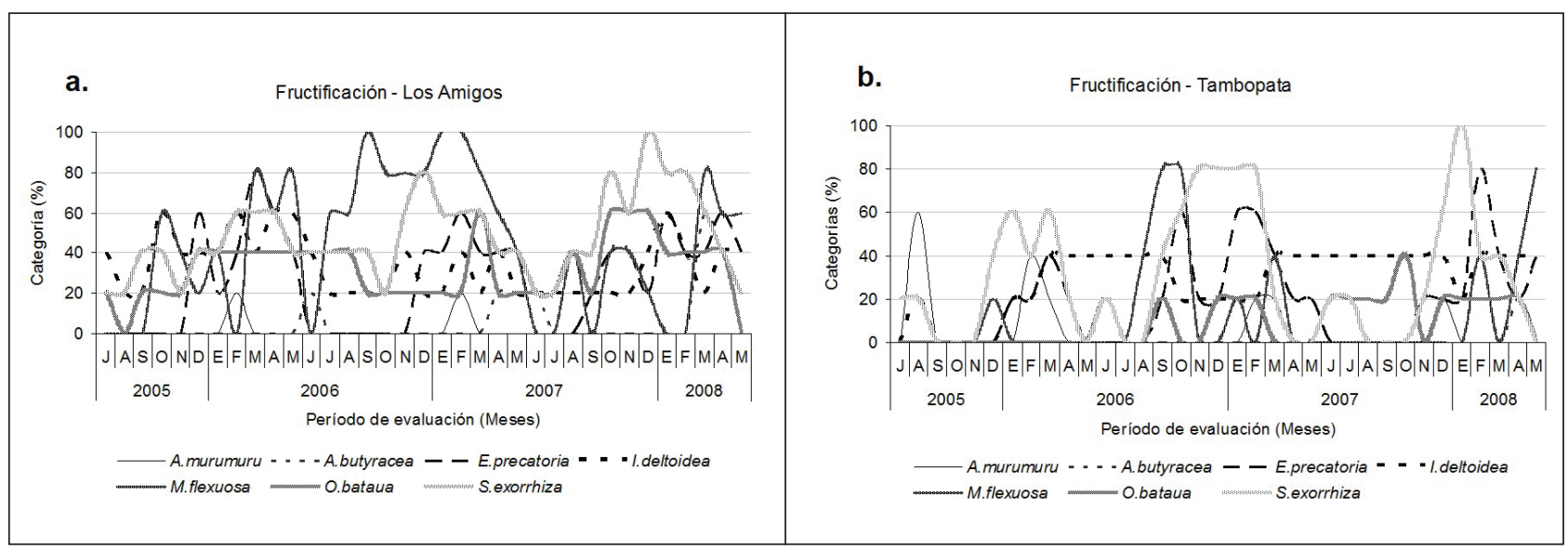

Figura 4. Patrones de fructificación poblacional de las palmeras arborescentes nativas en la localidad: a. Los Amigos b. Tambopata.

\section{Comportamiento fenológico de las especies evaluadas}

\section{Astrocaryum murumuru}

Palmeras solitarias de hasta $10 \mathrm{~m}$ de altura, flores diclino monoicas, con frutos obovoides de hasta $5 \times 3 \mathrm{~cm}$, comestibles, con propiedades medicinales y cosméticas. Nombre vernacular: "Huicungo" (Vásquez, 1997; Balslev et al., 2008).

En Los Amigos (Figura 5a), presentó una floración (incluyendo estadios de botón y flor) de patrón subanual, la producción de flores dura 5,00 $\pm 2,16$ meses (Tabla 2). Los picos de floración más altos en enero del 2005 y en diciembre del 2006 muestran un $60 \%$ de productividad, abarcando en el 2006 el final de la época seca y casi toda la época húmeda (septiembre-marzo). La fructificación mostró un patrón anual con picos máximos en febrero de cada año de evaluación, con una duración de $1 \pm 1,15$ meses (Tabla 2) y con la más baja productividad (20\%) entre enero y marzo (época húmeda).

En Tambopata (Figura 5b), la floración tuvo un patrón anual pero con episodios que duraron hasta 4,25 $\pm 2,75$ meses (tabla 2) entre el final de la época seca (octubre) e inicios de la época húmeda (noviembrefebrero, excepcionalmente hasta mayo). Los picos de producción floral van desde $20 \%$ como durante la época seca (agosto-octubre) del 2007 hasta 60\% en el mes de enero de cada año. Posteriormente, la fructificación muestra un patrón anual con episodios cortos de una duración de 3,25 $\pm 1,26$ meses. El pico de fructificación fue de $60 \%$ durante el comienzo de la época seca (agosto 2005), adicionalmente se observaron episodios de productividad decreciente como en el 2006 con un $40 \%$ y entre los años 2007-2008 con un 20\% de productividad.

Tabla 2. Tiempo de la floración y fructificación a nivel poblacional (media \pm desviación estándar) de sietes especies de palmeras arborescentes nativas durante el período de evaluación julio 2005 - mayo 2008.

\begin{tabular}{lcccc}
\hline \multirow{1}{*}{\multicolumn{1}{c}{ Especies }} & \multicolumn{2}{c}{ Floración } & \multicolumn{2}{c}{ Fructificación } \\
\cline { 2 - 5 } & $\begin{array}{c}\text { Tambopata } \\
\dot{\mathbf{X}} \pm \text { SD }\end{array}$ & $\begin{array}{c}\text { Los Amigos } \\
\dot{\mathbf{X}} \pm \text { SD }\end{array}$ & $\begin{array}{c}\text { Tambopata } \\
\dot{\mathbf{X}} \pm \text { SD }\end{array}$ & $\begin{array}{c}\text { Los Amigos } \\
\dot{\mathbf{X}} \pm \text { SD }\end{array}$ \\
\hline Astrocaryum murumuru & $4.25 \pm 2.75$ & $5.00 \pm 2.16$ & $3.25 \pm 1.26$ & $1 \pm 1.15$ \\
Attalea butyracea & $7.25 \pm 4.35$ & $1.25 \pm 0.95$ & $1.00 \pm 2.00$ & $2.25 \pm 1.71$ \\
Euterpe precatoria & $6.75 \pm 4.03$ & $5.25 \pm 4.57$ & $6.75 \pm 4.03$ & $5.50 \pm 3.69$ \\
Iriartea deltoidea & $6.25 \pm 1.26$ & $7.75 \pm 3.77$ & $6.25 \pm 3.30$ & $5.75 \pm 2.21$ \\
Mauritia flexuosa & $1.50 \pm 1.00$ & $1.75 \pm 1.26$ & $3.50 \pm 1.29$ & $6.50 \pm 3.69$ \\
Oenocarpus bataua & $6.25 \pm 3.20$ & $7.25 \pm 3.77$ & $4.75 \pm 3.77$ & $6.50 \pm 2.38$ \\
Socratea exorrhiza & $2.75 \pm 2.06$ & $5.00 \pm 2.94$ & $5.75 \pm 2.06$ & $7.50 \pm 2.89$ \\
\hline
\end{tabular}




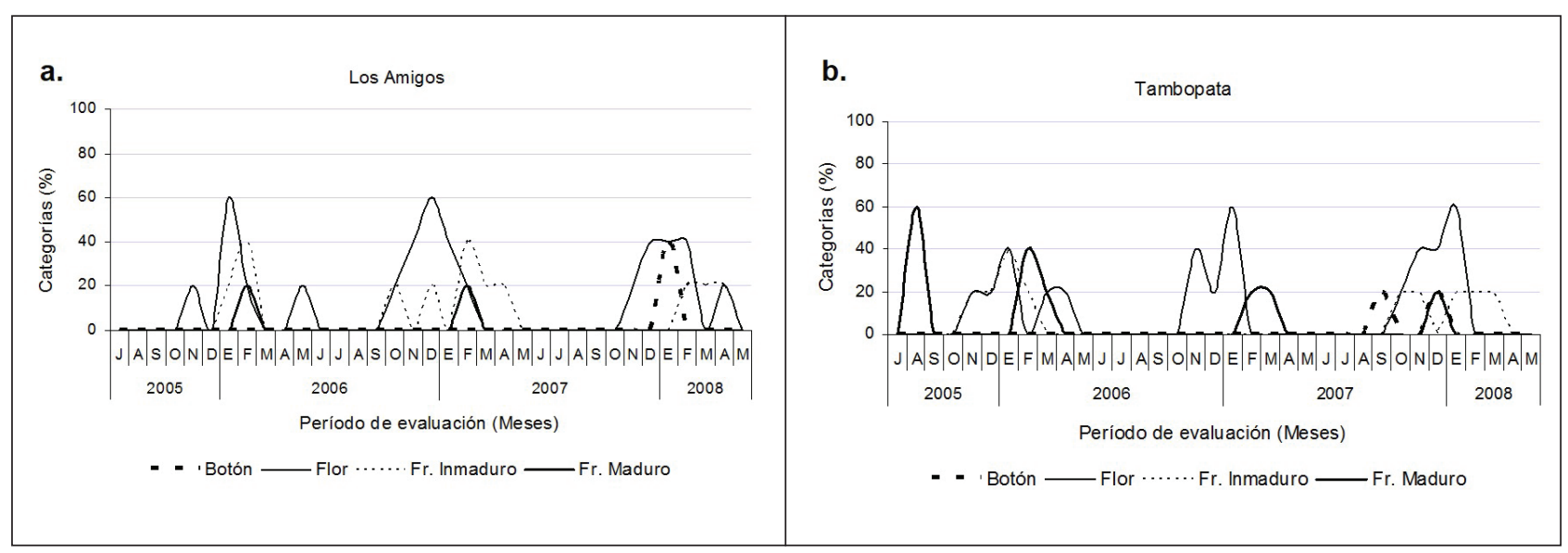

Figura 5. Fenología reproductiva de Astrocaryum murumuru en a. Localidad de Los Amigos durante el período de evaluación julio 2005mayo 2008. b. Localidad Tambopata durante el período de evaluación julio 2005-mayo 2008.

\section{Attalea butyracea}

Palmeras caulescentes, solitarias, hasta $25 \mathrm{~m}$ de altura, flores diclino monoicas, con frutos ovoides, $6-11 \times 5.5$ $\mathrm{cm}$, frutos y semillas comestibles, raíces utilizadas como medicina hepática. Nombre vernacular: "Shapaja", "Sheebon” (Vásquez, 1997; Balslev et al., 2008).

La floración en Los Amigos (Figura 6a) mostró un patrón anual, casi imperceptible entre el 2005 y 2006, pero con periodos más discernibles a partir del 2007 durante la época seca, cuando el pico de floración de $20 \%$ sucedió en julio y durante un corto periodo de 1,25 $\pm 0,95$ meses (Tabla 2). Durante la transición de flor a fruto inmaduro se observó un patrón continuo de duración prolongada pero irregular con picos hasta $60 \%$ durante la transición de época seca a húmeda y con una duración constante en la época húmeda, hasta alcanzar el episodio de fruto maduro en el que la fructificación se revierte a un patrón anual. La fructificación tiene una duración de 2,25 $\pm 1,71$ meses (Tabla 2). Durante el 2005 no se registraron frutos maduros, es sólo a partir del 2006 que se registró un $20 \%$ de productividad a inicios de la época seca (mayo-julio). En los años siguientes la duración de la fructificación se amplía levemente en el 2007 (marzo - julio) y también se observa un incremento de productividad durante el 2008 (60\%).

66

En Tambopata (Figura 6b), la floración mostró un patrón anual a continuo (desde episodio botón a flor) alcanzando su máximo en enero del 2007 con una productividad de $80 \%$ en la época húmeda (2006-2007) y con una duración de 7,25 $\pm 4,35$ meses (Tabla 2). Al contrario de los sucesos anteriores, en la fructificación se observó inicialmente un patrón continuo (episodio fruto inmaduro) y posteriormente un patrón subanual único en el 2008, con una duración de $1.00 \pm 2.00$ meses (Tabla 2) y con un pico de $40 \%$ de productividad en febrero (época húmeda).

\section{Euterpe precatoria}

Palmeras solitarias medianas a grandes hasta $20 \mathrm{~m}$, flores diclino-monoicas, tallo con una coloración gris y raíces adventicias rojas en la base, frutos globosos purpúreos de 12 - $14 \mathrm{~mm}$ de diámetro, la yema foliar y los frutos son comestibles, las raíces utilizadas como medicina para malaria, hepatitis y fiebre amarilla. Nombre vernacular: "Huasaî" (Vásquez, 1997; Balslev et al., 2008).

En Los Amigos (Figura 7a) presentó un patrón de floración subanual con una duración de 5,25 $\pm 4,57$ meses (Tabla 2) que sucede durante la transición de la época seca a la húmeda. La floración presenta dos picos del $60 \%$, el primero en la época seca en el mes de agosto-setiembre en el 2006 y el segundo en julio del 2007. La fructificación tuvo inicialmente un patrón continuo con máximos de hasta $80 \%$ durante los inicios de la época húmeda (septiembre u octubre, variando dependiendo de la precipitación); luego cambia a un patrón subanual con una duración de 5,50 $\pm 3,69$ meses (Tabla 2) observado durante la época húmeda. La máxima productividad de frutos alcanzó el $80 \%$ durante marzo del 2006. 


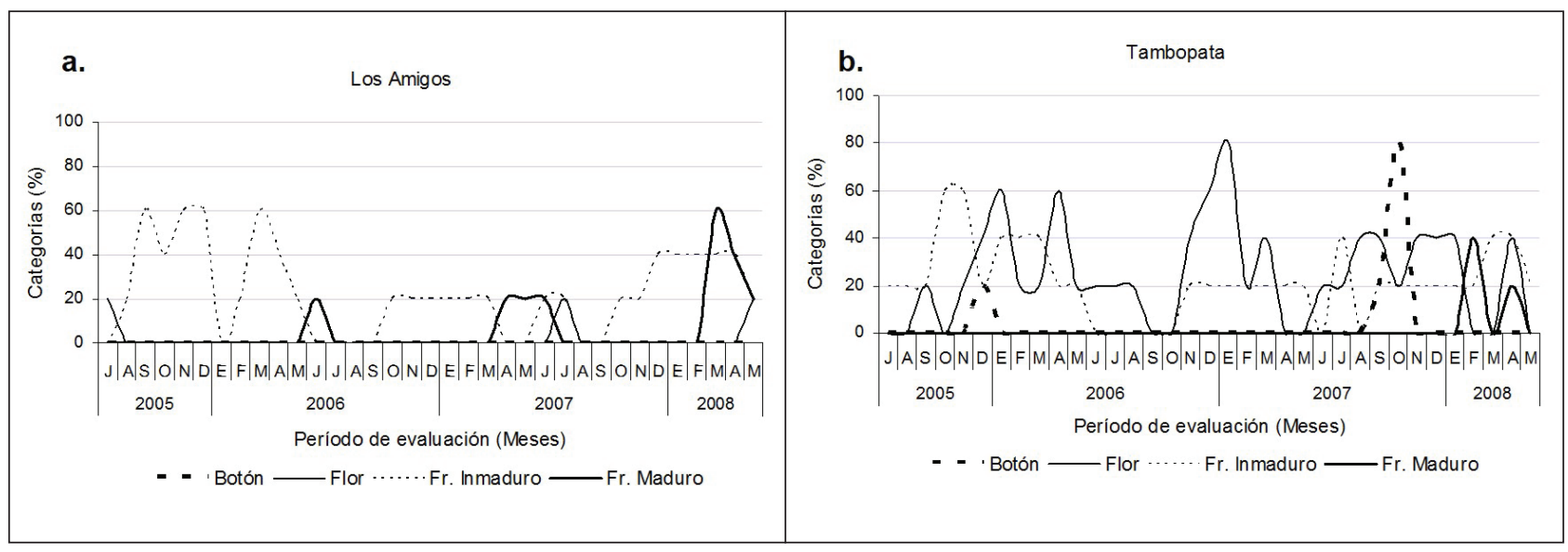

Figura 6. Fenología reproductiva de Attalea butyracea en a. Localidad de Los Amigos durante el período de evaluación julio 2005-mayo 2008. b. Localidad Tambopata, durante el período de evaluación julio 2005-mayo 2008.

Ambos eventos, floración y fructificación muestran un patrón subanual en Tambopata (Figura 7b) y una duración de 6,75 $\pm 4,03$ meses (Tabla 2). Independientemente, en la floración los valores máximos se observaron en la época seca, alcanzando un $60 \%$ de productividad en julio del 2007. En la fructificación se obtuvo el valor máximo de $100 \%$ en la época húmeda durante el estadío de fruto inmaduro, sin embargo solamente se obtuvo una productividad considerable del $80 \%$ en febrero del 2008 para el estadío de fruto maduro. La duración de la fructificación mostró un ligero alargamiento en el año 2007, año en que también se registraron frutos desde agosto (mes considerado como época seca propiamente dicha).

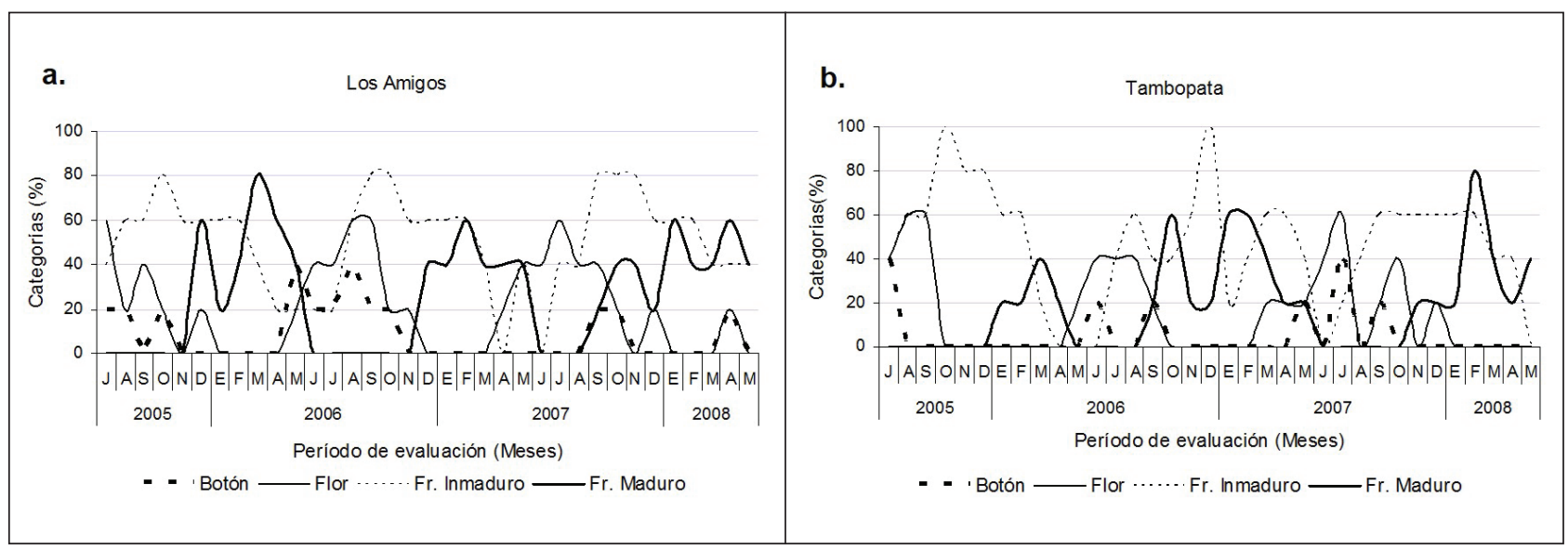

Figura 7. Fenología reproductiva de Euterpe precatoria en a. Localidad de Los Amigos durante el período de evaluación julio 2005-mayo 2008. b. Localidad de Tambopata durante el período de evaluación julio 2005-mayo 2008. 


\section{Iriartea deltoidea}

Palmas solitarias de 20-30 m de alto, tallo cilíndrico a veces ventricoso, raíces epigeas hasta $3.5 \mathrm{~m}$, flores diclino-monoicas, frutos globosos, 2-3 cm de diámetro, raíces utilizadas como medicina hepática y el tronco para acabo de pisos de interiores. Nombre vernacular: "Pona”, "Huacrapona" (Vásquez, 1997; Pennington et. al., 2004; Balslev et al., 2008).

La floración en Los Amigos (Figura 8a) mostró un patrón continuo durante los años evaluados, con una duración de 7,75 $\pm 3,77$ meses (Tabla 2). Durante el 2005 y 2006 los picos de productividad del $40 \%$ se alcanzan en la época húmeda (diciembre). Posteriormente, en el 2007 se observa el mismo valor de $40 \%$ pero durante la transición de época seca a húmeda (agosto, setiembre y octubre). De igual manera, la fructificación presentó un patrón continuo, alcanzando máximos de productividad (80\%) durante el estadío de fruto inmaduro en la época húmeda; durante el estadío de fruto maduro se observa un ligero cambio a un patrón subanual entre el 2005 y 2006. La fructificación tiene una duración de 5,75 \pm 2,21 meses (Tabla 2) y ocurre principalmente durante la transición de época seca a húmeda, imposibilitando la determinación del mes con mayor productividad (60\%).

Así mismo, la floración en Tambopata (Figura 8b) osciló entre 20 y $40 \%$ con un patrón anual, con el pico de productividad (estadío flores) en agosto y octubre, y con una duración de 6,25 $\pm 1,26$ meses (Tabla 2). A continuación, la fructificación presentó un patrón continuo, con una duración de 6,25 $\pm 3,30$ meses (Tabla 2), mostrando inicialmente un valor máximo de productividad (60\%) durante el estadío de fruto inmaduro, descendiendo luego al $40 \%$.

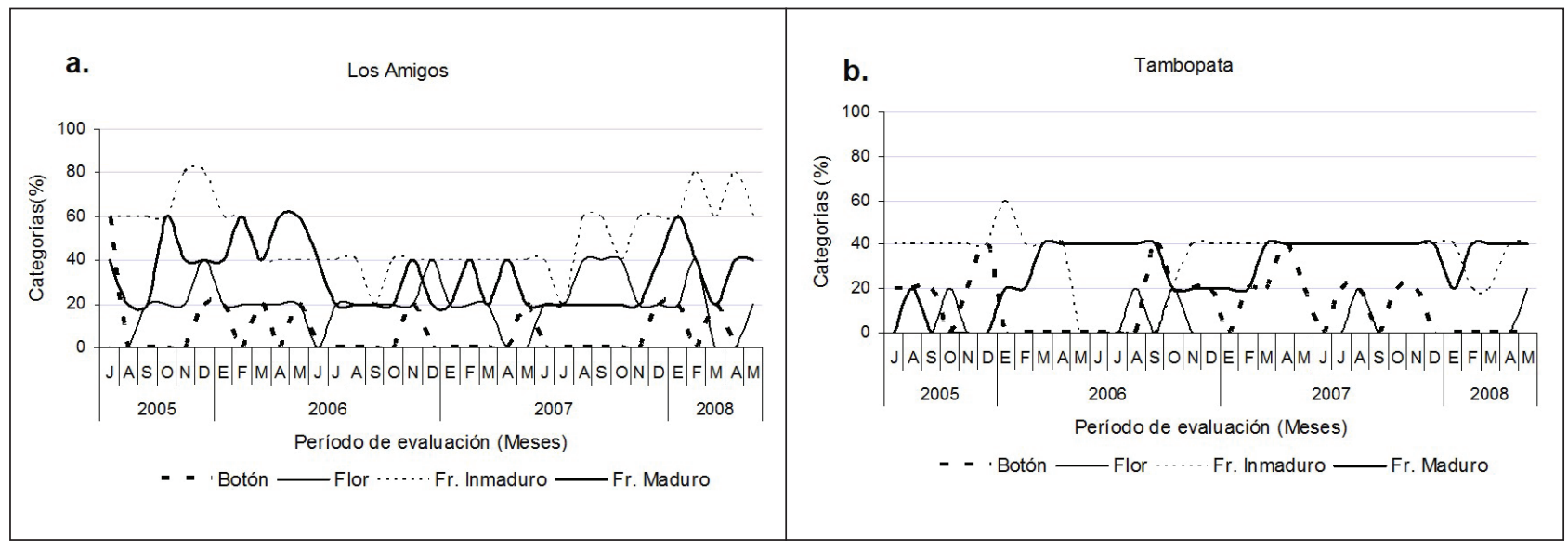

Figura 8. Fenología reproductiva de Iriartea deltoidea en a. Localidad de Los Amigos durante el período de evaluación julio 2005-mayo 2008. b. Localidad de Tambopata durante el período de evaluación julio 2005-mayo 2008.

\section{Mauritia flexuosa}

Palmera de 20-30 m (excepcionalmente $50 \mathrm{~m}$ ) de alto, flores diclino dioicas, fruto drupa subglobosa de 4-7 x 3-5 $\mathrm{cm}$, múltiples usos: alimenticio, medicinal, cosmético, en construcción, herramientas, considerada la palmera con mayor aprovechamiento en el Perú. Nombre vernacular: "Aguaje”. (Vásquez, 1997; Pennington et al., 2004; Balslev et al., 2008; Trujillo-Gonzalez et al., 2011).

En Los Amigos, la población de Mauritia flexuosa presentó una floración (Figura 9a) con patrón anual y con una duración promedio de 1,75 $\pm 1,26$ meses (Tabla 2) durante la época húmeda, alcanzando un máximo de productividad en noviembre del 2005 (100\%). La fructificación presentó una duración de 6,50 \pm 3,69 meses en un patrón continuo (estadío fruto inmaduro) a subanual (estadío fruto maduro), pero presente a lo largo de toda la evaluación. La fructificación mostró picos de productividad del $100 \%$ en septiembre (2006), enero y febrero (2007).

La floración en Tambopata (Figura 9b) presentó un patrón anual ligado a la época húmeda con una duración de 1,50 
$\pm 1,00$ meses (Tabla 2), alcanzando un valor máximo en octubre del 2005 y disminuyendo en los años posteriores a valores entre $20 \%$ y $60 \%$. La fructificación mostró un patrón subanual predominantemente durante la época seco-húmeda simulando un patrón anual y con máximos de productividad del $100 \%$ en el estadío de fruto inmaduro y $80 \%$ en el estadío de fruto maduro. La duración de la fructificación fue de 3,50 \pm 1,29 meses (Tabla 2).

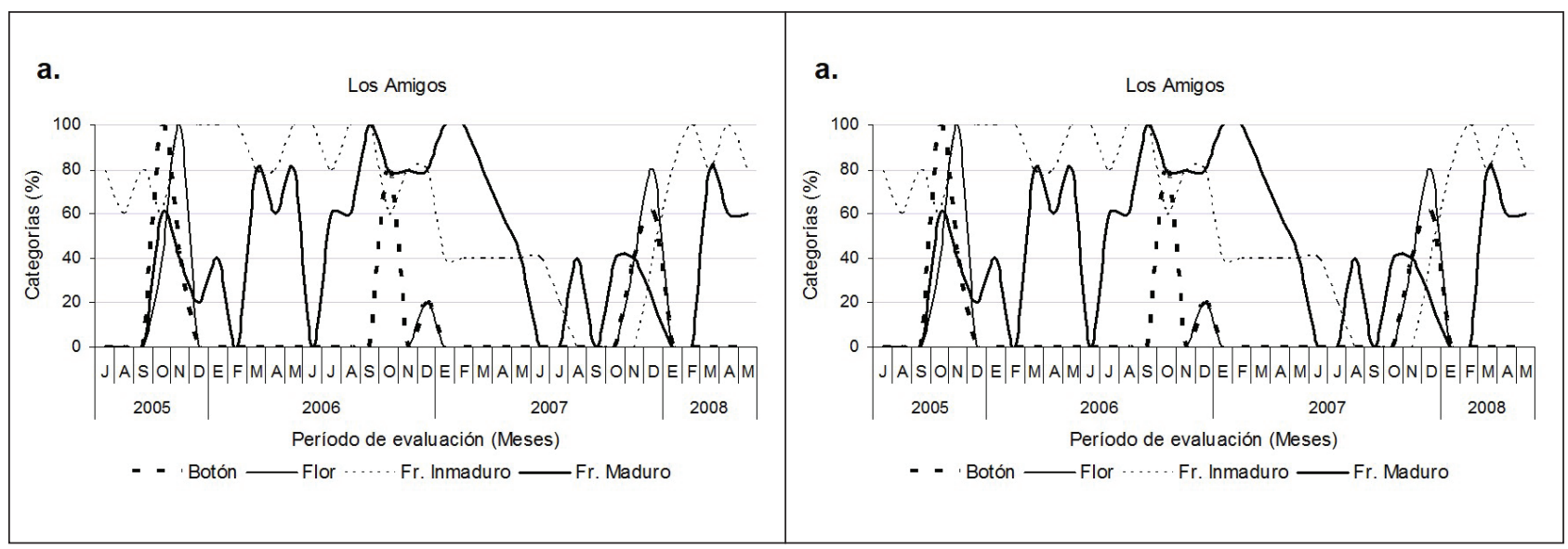

Figura 9. Fenología reproductiva de Mauritia flexuosa en a. Localidad de Los durante el período de evaluación julio 2005-mayo 2008. b. Localidad de Tambopata durante el período de evaluación julio 2005-mayo 2008.

\section{Oenocarpus bataua}

Palmera de 5-25 m de alto, tallo solitario o cespitoso, flores diclino monoicas, frutos ovoides comestibles de 2,5-4 x 2-3 cm, utilizada en la extracción de aceite y como medicina de hepatitis, fiebre y malaria. Nombre vernacular: "Hunguraui”, "Unguraui” (Vásquez, 1997; Pennington et al., 2004; Balslev et al., 2008).

En Los Amigos (Figura 10a), la floración presentó un patrón subanual a continuo, con una duración de $7,25 \pm 3,77$ meses (Tabla 2) y con picos máximos de productividad de $40 \%$ generalmente en la época húmeda. En la fructificación se observó un patrón continuo, con una duración de 6,50 $\pm 2,38$ meses (tabla 2) y con picos que oscilan entre 60 y $80 \%$ durante la época húmeda de los años 2007 y 2008.

En Tambopata (Figura 10b), la floración mostró inicialmente un patrón anual (estadío botón) y posteriormente un patrón subanual (estadío flor) con un pico máximo de productividad del $80 \%$ durante marzo del 2007, y con una duración promedio de 6,25 $\pm 3,20$ meses (Tabla 2). La fructificación presentó un patrón subanual con valores máximos entre 40 a $60 \%$ en el 2007 pero observable desde el 2006 durante época húmeda principalmente y con una duración de 4,75 \pm 3,77 meses (Tabla 2).

\section{Socratea exorrhiza}

Palmera de $20 \mathrm{~m}$ altura, con raíces epigeas de 2-3 m de largo, flores monoclino monoicas, frutos elipsoideovoide, $2,5 \times 3,5 \mathrm{~cm}$, estípite ampliamente utilizado para los pisos en las casas amazónicas. Nombre vernacular: "Cashapona”, "Paschi” (Vásquez, 1997; Pennington et al., 2004; Balslev et al., 2008).

En Los Amigos (Figura 11a) la floración presentó un patrón subanual con una duración de 5,00 \pm 2,94 meses (Tabla 2). La productividad varió del 40 al 60\% y ocurre principalmente en la transición de época húmeda a seca desde el 2005 al 2007. La fructificación presentó un patrón continuo a subanual con una duración de $7,50 \pm 2,89$ meses (Tabla 2) y con picos de hasta $100 \%$ de productividad en diciembre del 2006 y 2007, generalmente durante época húmeda.

En Tambopata (Figura 11b) la floración mostró un patrón anual a subanual, con una duración de 2,75 $\pm 2,06$ meses (Tabla 2), alcanzando picos de productividad de $40 \%$ en época seca como por ejemplo durante junio del 
2006. La fructificación mostró un patrón subanual con una duración de 5,75 \pm 2,06 meses ( 2) alcanzando un máximo de $100 \%$ de productividad y con valores mínimos del 20\% durante época seca (junio y julio) a lo largo de toda la evaluación. Cabe destacar que se observaron picos de productividad adicionales durante la época húmeda, por ejemplo un marcado incremento al 80\% durante el 2006 y 2007.

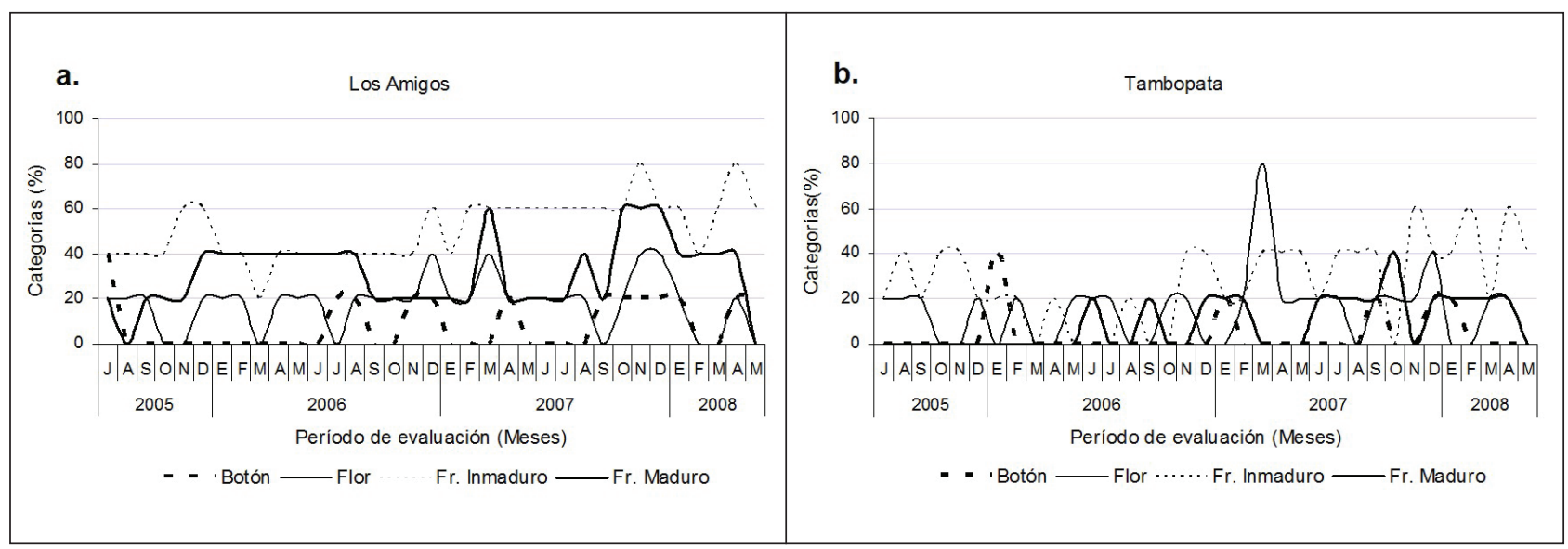

Figura 10. Fenología reproductiva de Oenocarpus bataua. a. Localidad de Los Amigos durante el período de evaluación julio 2005-mayo 2008. b. Localidad de Tambopata durante el período de evaluación julio 2005-mayo 2008.

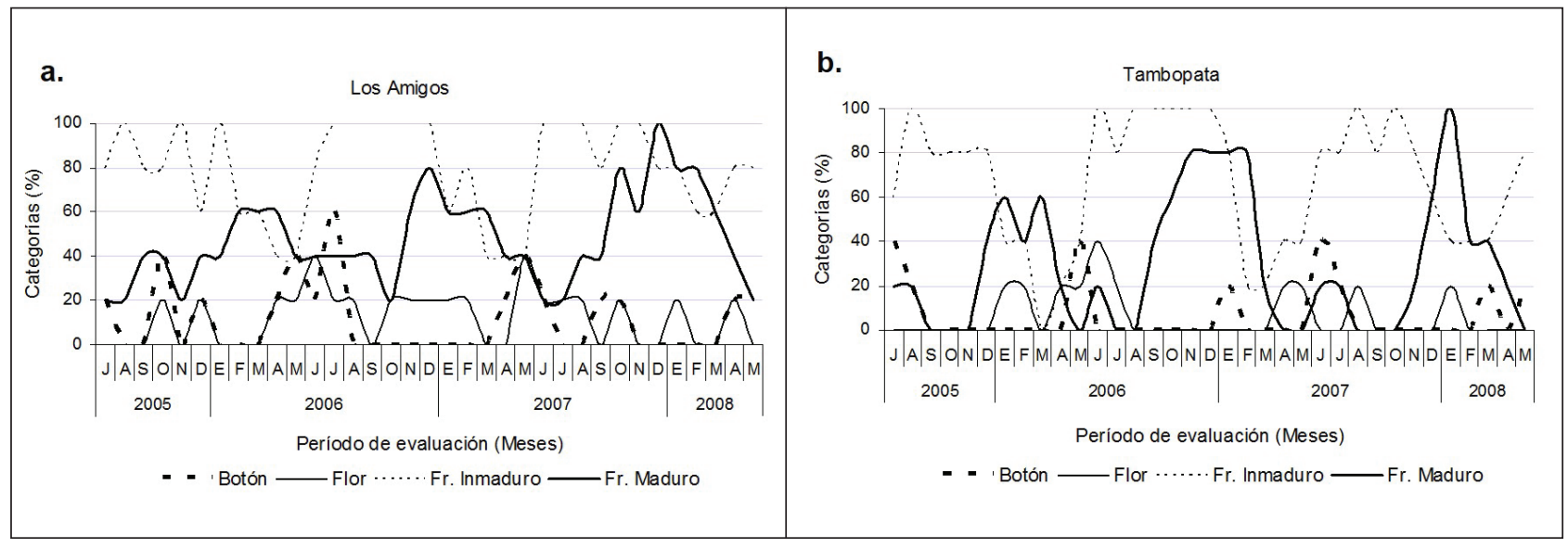

Figura 11. Fenología reproductiva de Socratea exorrhiza. a. Localidad de Los Amigos durante el período de evaluación julio 2005-mayo 2008. b. Localidad de Tambopata durante el período de evaluación julio 2005-mayo 2008.

70

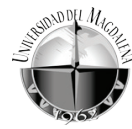

\section{DISCUSIÓN}

Los patrones fenológicos obtenidos de 176 individuos, distribuidos en 7 especies de palmeras amazónicas son particulares para esta área de estudio, como lo mencionan estudios anteriores realizados en palmeras neotropicales (Ibarra-Manriquez, 1992; Seres y Ramírez, 1993; Reynel et al., 2003; Haugaasen y Peres, 2005; Cabrera y Wallace, 2007), debido a que las variaciones en la estacionalidad del clima afectan directamente la fenología reproductiva de cada especie de palmera independientemente; así como otras variaciones anuales 
tales como luz, fertilidad del suelo, composición y estructura florística (Gentry y Ortiz, 1993) de los bosques que concentra el departamento de Madre de Dios.

Las palmeras amazónicas presentan fenofases con duraciones supra-anuales, como lo descrito por Rojas y Stiles (2009) con O. bataua. Pero existen algunas especies del género Euterpe que presentan fenofases anuales (Lara, 2011) así como pudimos observar durante la evaluación. La floración, iniciando con los botones florales, recibió influencia principalmente de la precipitación durante su inicio, e incrementando la producción de flores, de acuerdo a Cabrera y Wallace (2007) que menciona que durante este inicio de época húmeda hay un crecimiento de estas estructuras, debido a su exposición. En esta evaluación para ambas localidades, la especies E. precatoria y $S$. exorrhiza, no se ajustan a este patrón, registrando mayor producción (40 - 60\%) de botones durante la época seca. En ambas especies, la floración se inicia en la época húmeda pero la mayor productividad es constante hasta la época seca, siendo la más productiva S. exorrhiza (60\%). Así mismo, se registró una escasez de producción floral en las especies A. butyracea y A. murumuru $(0-20 \%)$. Ambas diferencias de productividad se atribuyen a la humedad y al drenaje del suelo del bosque húmedo tropical de transición a subtropical (bh-T/S), ecosistema frágil y complejo (Rodríguez, 1995).

Las flores maduras en estas especies de palmeras aparecieron mayormente en época húmeda o a inicios de ella (Cabrera y Wallace, 2007), principalmente M. flexuosa (100\%) abundante a nivel poblacional, y A. butyracea $(80 \%)$ con mayor producción sólo en Tambopata (Figuras 10a y b), se postula que la floración en esta especie constituye una fuente alimenticia importante para los diversos polinizadores, principalmente coleópteros pertenecientes a las familias Netidulidae, Curculionidae y Cucujidae, los cuales son atraídos por el aroma de sus flores (Storti, 1993) y son abundantes durante época húmeda en estos ecosistemas. Las especies que presentaron patrones parcialmente semejantes entre localidades de evaluación fueron A. murumuru, E. precatoria, I. deltoidea, $M$. flexuosa y S. exorrhiza, mientras que las demás palmeras tuvieron comportamientos diferentes en cada localidad, por ejemplo O. bataua en Los Amigos presentó presentó una baja productividad y en Tambopata por el contrario mostró una producción de hasta el $80 \%$, pero con un patrón asincrónico en ambas localidades. En el caso de $A$. butyracea, solamente se observa una notable producción $(80 \%)$ en Tambopata mientras que en Los Amigos sólo llega al 20\%.

Durante la fructificación los resultados fueron contrastantes entre las localidades evaluadas, ya que hay mayor productividad en Los Amigos en la mayoría de especies, pero con una exuberante sobreproducción de frutos de $M$. flexuosa con un patrón supra-anual y asincrónico para ambas localidades. Se observa cierta estacionalidad en algunas especies, pero la mayoría inicia su fructificación en la transición de época seca a húmeda. Existen estudios que mencionan que el grado de germinación y disponibilidad de fruto podría estar relacionado con este patrón de estacionalidad (IbarraManríquez, 1992), lo cual fue observado in situ en cada localidad por otros componentes del proyecto multidisciplinario, ya que se tuvo observación directa sobre la captura y monitoreo de especies herbívoras como Tapirus terrestris, Tayassu peccari, Ara ararauna, Ara macao, Ara chloroptera, y durante este tiempo se vio de cerca y cuán grande puede llegar a ser el home range de estos animales que transportan millones de frutos y semillas de palmeras, listos para ser germinados. De igual manera, se apreció la preferencia de estos herbívoros por ciertas especies de palmeras, como sucede con T. peccari que consume alrededor de 37 especies de palmeras (Beck, 2006) y que a finales de la época seca muestra cierta preferencia por $A$. murumuru, $M$. flexuosa, e I. deltoidea que forman parte de su dieta principal (Kiltie, 1981). Sin esta predación, la germinación de semillas de esas especies de palmeras se incrementaría en un 6000\% (Wyatt y Silman, 2004). Por otro lado, psitácidos de las especies Ara ararauna, A. macao y A. chloroptera, prefieren alimentarse de la mayoría de frutos de las especies evaluadas, pero escogen individuos de algunas especies para convertirlos en nidos, especialmente las palmeras de troncos ventricosos como Iriartea deltoidea, y los troncos muertos de M. flexuosa (Brightsmith, 2005).

Así mismo, si se tiene en cuenta la disponibilidad de frutos en este estudio, la mayor disponibilidad se ubicó en la localidad de Los Amigos más que en Tambopata durante el mismo periodo, lugar en el que la especie M. flexuosa tuvo frutos maduros accesibles tanto en época seca y época húmeda, pero $S$. exorrhiza ofreció un comportamiento parecido (menos intenso) en ambas localidades.

Finalmente, con este estudio se postula que la constante presión de caza como factor antrópico y la presencia de 
colpas como factor biótico, lograron una concentración obligada de la fauna sobre áreas protegidas, como en Los Amigos, en donde el área de evaluación pertenece a la Asociación para la Conservación de la Cuenca Amazónica (ACCA) haciendo que el efecto de dispersión de las especies vegetales comúnmente consumidas, como lo son las palmeras arborescentes, sea limitado y con una densidad significativa; a diferencia de Tambopata, área protegida con mayor extensión pero con distintas condiciones, entonces eventos como la floración y fructificación de palmeras, por ejemplo, se realizan con éxito también, pero con una densidad inferior de estos individuos. Resultan importantes los alcances sobre la fenofases de las palmeras tropicales, en especial las especies útiles, ya que no presentan igual distribución en todos los bosques húmedos, se agrupan de acuerdo a diversos factores, siendo la afinidad por el tipo de suelo y el grado de humedad de ellos, los principales requerimientos para su desarrollo (Kahn, 1991) pero no los únicos, siendo necesario generar mayor interés en desarrollar estudios que logren entender total o parcialmente los distintos aspectos que puede ofrecer la biología de las palmeras tropicales.

\section{AGRADECIMIENTOS}

El presente estudio se desarrolló en la ciudad de Madre de Dios, formando parte del proyecto AREAS-Amazonía de World Wildlife Fund Inc. - Perú, financiado por World Wildlife Fund - Washington y Gordon and Betty Moore Fundation. Agradecemos a la Dirección General Forestal y de Fauna Silvestre (DGFFS) y al Servicio Nacional de Áreas Naturales Protegidas (SERNANP) por los permisos concedidos, y a The Botanical Research Institude of Texas por Atrium Biodiversity Information System (ATRIUM) por facilitarnos los datos meteorológicos de Madre de Dios. Expresamos un agradecimiento especial a George Powell por todo su apoyo en la coordinación del proyecto AREAS; de igual manera a Ruben Aviana, Marlon Guerra, Rufo Bustamante, Mario Alvites, Juan Racua y Lucas Huaymana, por su apoyo en la fase de campo para la realización de este trabajo. Agradezco también a Nuria Otmani de la Universidad Complutense de Madrid, Edgardo M. Ortiz de la Universidad de Texas en Austin y a Paula Picardo de Stockhom University, por la corrección y revisión del manuscrito.

\section{BIBLIOGRAFÍA}

ATRIUM version 1.8, Botanical Research Institute of Texas [on line]. Data base available of Botanical Research Institute of Texas on Weather Stations from Atrium Biodiversity Information System (ATRIUM), [date accessed: Julio 2005 - Mayo 2008]. Also available in: < http://atrium. andesamazon.org/meteo_station_list.php $>$.

Balslev, H., C. Grandez, N. Paniagua-Zambrana, A. Møller, y S. Hansen. 2008. Palmas (Arecaceae) útiles en los alrededores de Iquitos, Amazonía Peruana. . Revista Peruana de Biología 15 (1): 121-132.

Beck, H. 2006. A review of peccary-palm interaccions and their ecological ramifications across the neotropics. Journal of Mammalogy 87 (3): 519-530.

Brightsmith, D. 2005. Parrot nesting in southeastern Peru: Seasonal patterns and keystone trees. Wilson Bulletin 117(3): 296-305.

Cabrera, H. y R. Wallace. 2007. Densidad y distribución espacial de palmeras arborescentes en un bosque preandino-amazónico de Bolivia. Ecología en Bolivia 42 (2): 121-135.

Del Castillo, D., E. Otárola y L. Freitas. 2006. Aguaje: La maravillosa palmera de la Amazonía. Instituto de Investigaciones de la Amazonía Peruana. 54p.

Encarnación F. 1993. El bosque y las formaciones vegetales en la Llanura Amazónica del Perú. ALMA MATER UNMSM.: 95-114.

Fournier, L. A. 1974. Un método cuantitativo para la medición de características fenológicas en árboles. Turrialba 24: 422-423.

Gentry, A. y R. Ortiz. 1993. Patrones de composición florística en la Amazonía Peruana. En. Kalliola, R., Puhakka, M. y Danjoy, W. (ed.), Amazonía Peruana: Vegetación húmeda tropical en el llano subandino. PAUT-ONERN. Gummerus Printing, Jyväskylä, Finland. 155-166 pp.

Haugaasen, T. y C. A. Peres. 2005. Tree phenology in adjacent Amazonian flooded and unflooded forest. Biotropica 37(4): 620-630. 
Henderson, A., G. Galeano y R. Bernal. 1995. Field Guide to the Palms of the Americas. Princeton University Press, Princeton, New Jersey, USA. 65 p.

Holdridge, L. R. 1987. Ecología basada en zonas de vida. San José, CR. llCA. 216 p.

Ibarra-Manríquez, G. 1992. Fenología de las palmas de una selva cálido húmeda de México. Bulletin.de L’Institut. Français d'Etudes Andines 21 (2): 669-683.

Kahn, F. 1991. Palms as key swamp forest resources in Amazonia. Forest Ecology and Management. 38: 133-142.

Kahn, F. y K. Mejía. 1989. Las palmeras nativas de importancia económica en la Amazonía Peruana. Revista Folia Amazónica, 1 (1): 103- 116.

Kiltie, R. 1981. Distribution of palm fruits on a rain forest floor: Why white-lipped peccaries forage near objects. Biotropica 13 (2): 141-145.

Lara, C. E. 2011. Fenología reproductiva y demografía de la palma Wettinia kalbreyeri (Burret) en un Bosque Altoandino de Colombia. Universidad Nacional de Colombia Sede Medellín. Facultad de Ciencias Agropecuarias. Departamento de Ciencias Forestales. Posgrado en Bosques y Conservación Ambiental. 34 p.

León, B., J. Roque, C. Ulloa, N. Pitman, P. Jorgensen y A. Cano. 2006. El libro rojo de las plantas endémicas del Perú. Revista Peruana de Biología 13 (2): 9-971.

Loayza, A., R. Ríos y D. Larrea-Alcázar. 2006. Disponibilidad de recurso y dieta de murciélagos frugívoros en la Estación Biológica Tunquini, Bolivia. Ecología en Bolivia 41(1): 7-23.

Newstron, L.E., G.W. Frankie, H. G.Baker, y R.K. Colwell. 1994. Diversity of long term flowering patterns. pp 142-160. En: La Selva: ecology and natural history of a Neotropical rain forest. Mc. Dade, L.A., K. S. Bawa, H.A.Y. Hespenheidae, G.S Hartshorn. (Ed.), Chicago, US. University of Chicago Press. 142-160 p.

Pennington, T., C. Reynel, y A. Daza. 2004. Illustrated guide to the Trees of Peru. Spoelbeech-Artois Foundation. David Hunt, The Manse, Chapel Lane, Milborne Port, Sherborne, DT9 5DL, Inglaterra. 849 p.
Peres, C. A. 1994. Composition, density, and fruiting phenology of arborescent palms in a Amazonian terra firme forest. Biotropica 26: 285-294.

Reynel, C., T. Pennington, R. Pennington, C. Flores, y A. Daza. 2003. Árboles útiles de la Amazonía Peruana. Un manual con apuntes de identificación, ecología y propagación de las especies. Tarea Gráfica Educativa. Lima, Perú. 509 p.

Rodríguez, F. 1995. El recurso del suelo en la Amazonía Peruana, diagnóstico para su investigación. Instituto de Investigaciones de la Amazonía Peruana. IIAP. Documento Técnico. Iquitos, Perú. 59 p.

Rojas-Robles, R., G. Stiles, y Y. Muñoz-Saba. 2012. Frugivoría y dispersión de semillas de la palma Oenocarpus bataua (Arecaceae) en un bosque de los Andes colombianos. Revista de Biología Tropical 60 (4): 1445-1461.

Rojas, R. y G. Stiles. 2009. Analysis of a supra-annual cycle: reproductive phenology of the palm Oenocarpus bataua in a forest of the Colombian Andes. Journal of Tropical Ecology 25: 41-51.

Seres, A. y N. Ramírez. 1993. Floración y fructificación de monocotiledóneas en un bosque nublado venezolano. Revista de Biología Tropical 41 (1): 27-36.

Storti, E. F. 1993. Biología floral de Mauritia flexuosa Lin. fil., na região de Manaus, Amazonas, Brasil. Acta Amazonica 23 (4): 381.

Tobler, M., S. E. Carrillo-Percastegui, R. Leite Pitman, Mares y G. Powell. 2008. An evaluation of camera traps for inventorying large- and medium-sized terrestrial rainforest mammals. Animal Conservation 11: 169-178.

Trujillo-Gonzalez, J., M. Torres y E. Santana-Castaña. 2011. La palma de Moriche (Mauritia flexuosa L.f.) un ecosistema estratégico. Orinoquia 15(1): 62-70.

Tupayachi, R.; E. Martínez, y G. Powell. 2007. Avances en el estudio de los patrones fenológicos de cinco especies arbóreas de Tambopata Madre de Dios. Revista Q'ueñua 1: 37-42.

Vásquez, R.1997. Flórula de las Reservas Biológicas de Iquitos, Perú. Missouri Botanical Garden. St. Louis, USA. 1047 p. 
Wallace, A. R. 1853. Palm trees of the Amazon and their uses. John Van Voorst. Taylor y Francis, Red Lion Court, Fleet Street. London. 129 p.
Wyatt, J. y M. Silman. 2004. Distance-dependence in two Amazonian palms: effect of spatial and temporal variation in seed predator communities. Oecología 140: 26-35.

Fecha de recepción: 30/04/2014 Fecha de aceptación: 21/09/2014

Para citar este artículo: Ureta, M., P. Martínez, R. Tupayachi y A. Zúñiga. 2014. Fenología de palmeras arborescentes nativas de Madre de Dios - Perú. Revista Intropica 9: 60 -74 